ПЕДАГОГИКА

DOI: $10.26907 / 2074-0239-2019-57-3-206-211$

УДК 372.893

\title{
ФОРМИРОВАНИЕ ОБЩЕКУЛЬТУРНЫХ КОМПЕТЕНЦИЙ У ВЫПУСКНИКОВ ВЫСШИХ УЧЕБНЫХ ЗАВЕДЕНИЙ
}

\author{
(C) Лейсан Гаибова
}

\section{DEVELOPING GENERAL CULTURAL COMPETENCES IN GRADUATES OF HIGHER EDUCATION INSTITUTIONS}

\begin{abstract}
Leysan Gaibova
The article deals with the issues of teaching Homeland History in higher education institutions of our country. The relevance of the topic is explained by the fact that History is a compulsory subject in higher education system as it contributes to the creation of a new world outlook in the younger generation, oriented towards learning the objective laws of the society development. The article discusses the issues of creating a unified ideology under the conditions of the unstable situation in the world. Based on the analysis of the scientific works written by F. M. Nuriahmetova, V. G. Kholodnova, O. A. Pavlova, E. M. Rubaeva, D. K. Stozhko, S. S. Shalaeva, A. I. Nozhkina, I. V. Kleschevoy, A. V. Rychkova and others, the article suggests variants of problem-based classes of three types of complexity. In this case, when learning history, students are required to work independently, displaying different levels of analytical thinking. We emphasize the necessity of studying Homeland History in higher education institutions and reveal objective reasons for experiencing certain difficulties in mastering this discipline. Particular attention is paid to the creation of new methods for teaching History and implementation of effective teaching technologies and approaches into the educational process with the purpose of improving the quality of education.
\end{abstract}

Keywords: history education, history teaching, general cultural competences, innovative methods, problem-oriented approach, interactive approach.

В статье рассматриваются проблемы преподавания курса «История Отечества» в высших учебных заведениях нашей страны. Актуальность темы обоснована тем, что история является необходимым предметом в системе высшего образования, так как она способствует формированию нового мировоззрения молодого поколения, ориентированного на познание объективных законов развития общества. Затрагиваются вопросы создания единой идеологии в условиях нестабильной ситуации в мире. На основе анализа научных трудов Ф. М. Нуриахметовой, В. Г. Холоднова, О. А. Павловой, Э. М. Рубаевой, Д. К. Стожко, С. С. Шалаевой, А. И. Ножкиной, И. В. Клещевой, А. В. Рычкова и других разработаны варианты проведения проблемных занятий трех типов сложности, требующих от студентов при овладении историческими знаниями определенной степени самостоятельности и проявления разного уровня аналитического мышления. Доказывается необходимость изучения истории Отечества в высших учебных заведениях, раскрываются объективные причины, указывающие на сложность освоения этой дисциплины. Особое внимание акцентируется на создании новой методологии преподавания истории, на внедрении в учебный процесс эффективных методов и подходов к обучению с целью улучшения качества образования.

Ключевые слова: историческое образование, преподавание истории, общекультурные компетенции, инновационные методы, проблемно-ориентированный подход, интерактивный метод.

Значимость усовершенствования российской системы образования для социально-экономического и политического развития страны трудно переоценить. Это особенно актуально сейчас, когда наше правительство акцентирует внимание на необходимости осуществления экономического прорыва, основанного на новейших достиже- ниях науки и техники. В связи с этим основной проблемой образовательной системы является подготовка и выпуск специалистов, способных решать любые задачи в области своей профессиональной деятельности и хорошо ориентирующихся в социально-политических вопросах современного общества. Этому в большой степе- 
ни способствует применение в преподавании истории проблемно-ориентированного подхода, формирующего прогрессивное мировоззрение студентов. Кроме того, анализ исторической информации дает представление о роли России в мировом пространстве.

В исследованиях Д. К. Стожко, Ф. М. Нуриахметовой, В. Г. Холоднова, С. С. Шалаевой, О. А. Павловой, Э. М. Рубаевой, Е. А. Назыровой, Н. Д. Сапожниковой и других ученых особое внимание уделяется вопросам преподавания истории, ее роли в общеобразовательном процессе. Наиболее остро проблема в области исторического образования обозначилась в постсоветский период развития нашей страны, что исследователи связывают с утратой прежней идеологии, на которой строилась вся система образования, и с необходимостью создания новых ценностных ориентиров. Обновление педагогической составляющей исторической науки происходило путем пересмотра общепринятых исторических канонов и в условиях неоднозначности научных трактовок общественных процессов. С 2000-го года принимается новая программа исторического образования, в которой наряду с идеями плюрализма появляется новая концепция, отвечающая национальным интересам страны, воспитывающая молодежь с четкой гражданской позицией [Шалаева, Ножкина, с. 117]. Одним из важнейших факторов в процессе обновления исторического образования этого периода является осознание того, что преподавательская деятельность должна быть направлена на формирование ценностных ориентаций, уважительного отношения к прошлому нашей страны, на сохранение единства многонационального российского общества.

Процесс преобразования преподавательской практики исторической дисциплины претерпевает определенные трудности. Сфера образования отличается большим разнообразием концептуальных подходов к вопросам преподавания истории, в то время как требуется единая позиция по многим определяющим вопросам [Стожко Д., Стожко К., с. 89]. В условиях создавшегося неоднозначного представления о прошлом преподаватели осуществляют процесс обучения исходя из собственных мировоззренческих предпочтений ввиду отсутствия новой учебной литературы. Существует и другая трудность при осуществлении образовательного процесса исторической дисциплины, которая кроется в том, что наличие неопределенных субъективных взглядов на прошедшие исторические события порождает риски неправильного восприятия реалий истории и принижение значимости событий прошлых лет, искажение их смысла. Это может привести к разрушительным последствиям, связанным с утратой историей ее статуса социально значимой науки в российской образовательной системе. Важно отметить, что большое разнообразие литературы, в которой даются неоднозначные высказывания об исторических событиях, произошедших в ходе развития российского государства, иногда несущие в себе негативную оценку деятельности исторических лидеров, препятствует воспитанию у молодежи гражданской ответственности и формированию национальной гордости.

Преодолению перечисленных трудностей, по мнению многих ученых, способствует переход на современные образовательные стандарты. Необходимость нового, более широкого осмысления исторических процессов и нового понимания роли России в мировом сообществе в условиях происходящей глобализации является определяющим фактором для введения в систему образования новой методологии преподавания истории с внедрением компетентностного подхода [Сапожникова, с. 147]. Поиск новых направлений преподавания истории построен на познании логики исторической науки в соответствии с комплексом других научных знаний. Это должно способствовать не только освоению студентами новой информации, но и умению определять истинные общечеловеческие ценности при рассмотрении исторических фактов. Использование междисциплинарного подхода, основанного на определенной связи между научными отраслями и технологиями, способствует выработке у студентов способностей к системному и логическому мышлению и формированию у будущих специалистов общекультурных компетенций в комплексе с профильными знаниями [Нуриахметова, Холоднов, с. 71]. Современная методология системы образования не предусматривает полного отказа от традиционных форм преподавания ввиду того, что лекционно-книжная форма обучения обеспечивает получение студентами основной базовой информации, на основе которой в дальнейшем они могут строить собственные выводы и проводить самостоятельное исследование. Но в условиях, когда в учебный план заложено недостаточное количество часов для прохождения курса истории в полном объеме, традиционные методы обучения дают поверхностные знания и не способствуют глубокому осмыслению исторических процессов, в связи с чем возникает необходимость в новых подходах преподавания этой дисциплины.

Среди инновационных методов в преподавании истории одна из доминирующих ролей отво- 
дится методу проектов [Павлова, с. 115]. Проектная работа по истории предполагает исследование исторической проблемы путем эмоционального погружения в нее, что способствует лучшему восприятию исторических событий, отстранению от навязываемых критических оценок прошлого России и появлению собственного мнения относительно изучаемых явлений. Проектная деятельность ориентирована на приобретение студентами углубленных знаний и компетентности в области истории. Это возможно лишь в том случае, если исследовательская работа по истории будет глубоко содержательной, а доказательная база - логически обоснованной. В связи с этим одним из условий качественного выполнения проектной работы является умение студентов работать с историческими источниками. Работа с архивными документами и другим текстовым материалом ведет к развитию аналитического мышления, накоплению опыта самостоятельной исследовательской работы.

При изучении современных методов преподавания наиболее эффективными при получении систематизированных знаний по истории, в том числе при проведении вариативных курсов, являются интерактивные методы обучения [Рубаева, с. 210]. Основной акцент при использовании этих методов делается не на изложении курса дисциплины, а на способах получения знаний и умении их применять. При интерактивном способе ведения учебного процесса не допускается доминирование одной позиции и взглядов над другими. Решение сложных задач происходит при их коллективном обсуждении в условиях реализации мыслительных способностей студентов. Обучение в режиме диалога ведет к приобретению будущими выпускниками очень важных качеств: умения выслушивать противоположные мнения и на основе критического анализа всех точек зрения принимать продуманные решения.

Большое значение в российской системе образования уделяется изучению истории Отечества, вследствие того что государственная идеология, основанная на стремлении сохранения единства нашей нации, определяется через обращение к историческому прошлому России [Рычков, с. 83]. Изучение этой дисциплины невозможно без детального рассмотрения исторических событий с персонажами соответствующего периода, несмотря на ограниченность часов, отведенных на предмет истории в учебном плане. Изучение исторических личностей, их влияния на ход истории, оценка их роли в произошедших событиях с точки зрения закономерности исторических процессов остается одним из самых дискуссионных вопросов современности. Без углубленного изу- чения биографических фактов исторических деятелей невозможно постичь полную картину общественно-политического развития нашей страны. На практических занятиях по истории целесообразно проводить обсуждение нравственных ценностей и идей о преобразовании мира, преобладающих в определенные исторические эпохи. В результате этих курсов студенты, основываясь на самостоятельно полученной информации, учатся давать критическую оценку деятельности исторической личности, анализировать отрицательные и положительные стороны его влияния на судьбы людей. При изучении истории Отечества эффективным является использование интерактивных методов обучения, например, проведение занятия в форме викторины. Студентов заранее ставят в известность о необходимости повторения материала по теме, по которой будет проводиться викторина. Выбор темы основывается на каких-либо важных исторических событиях, знание которых является необходимым при освоении курса истории, например, «Внешняя политика России в XVIII-XIX вв.», «Отечественная война 1812 года и ее герои», «Роль Екатерины Великой в российской истории» и другие. Студенты делятся на три группы и по очереди отвечают на вопросы, получая баллы за правильные ответы. В качестве мотивации победившая группа студентов получает зачет по данной теме. По окончании викторины преподаватель может обсудить вопросы, на которые студенты не смогли дать правильные ответы.

Проблемно-интегративный метод обучения дает студенту возможность проводить анализ отличающихся друг от друга подходов к проблемам и событиям прошлого и выбрать из них тот, который ему самому покажется наиболее актуальным. Проблемно-ориентированный метод способствует формированию у студентов определенных навыков: самостоятельного мышления; критической оценки исторических явлений; умения выявлять проблему, выстраивать логическую цепочку рассуждений, применять на практике полученные знания, работать в коллективе.

Выработка этих навыков является процессом длительным, требующим постепенной и поэтапной подготовки. Необходимость предварительной подготовки к проведениям проблемноориентированных занятий обусловлена тем, что в исторической дисциплине знания приобретаются не экспериментальным путем и не путем непосредственного наблюдения, а посредством анализа исторических документов. Путь к истине лежит через исследование причинно-следственных связей событий прошлого и выявление истинных исторических фактов с определением их 
исторического места и конкретного объективного значения в глобальном масштабе.

Проблемное обучение делится на три уровня в зависимости от степени самостоятельности студента при решении проблемных вопросов: студент совместно с преподавателем ищет пути решения проблем, поставленных преподавателем; студент самостоятельно ведет поиск решения проблем, поставленных преподавателем; студент самостоятельно выдвигает проблему, находит пути ее решения, анализирует полученные выводы, делает обобщения.

На первом уровне проблемного обучения одним из самых действенных методов для усвоения полученных знаний и самостоятельного их переосмысления является проблемная лекция, которая начинается с формулирования проблемы в виде постановки вопроса по выбранной теме [Клещева, с. 206]. В ходе занятия преподаватель по мере изложения материала размышляет над поставленной проблемой, пытается привлечь студентов к поиску решений. Благодаря проблемным лекциям студенты учатся выстраивать логическую цепочку рассуждений и проводить анализ фактов. В качестве примера составим проблемную лекцию на тему: «Модернизация России во II половине XIX века». В конце занятия студентам предстоит ответить на поставленный преподавателем вопрос: «Какое значение имели реформы во II половине XIX века для развития России?» После коллективного обсуждения положения крестьян вследствие принятия в 1861 году Манифеста об отмене крепостного права преподаватель переходит к выявлению прогрессивного и негативного значения и других реформ, принятых Александром II: земской, судебной, военной, городской и в области народного образования. Исходя из полученных в ходе занятия знаний и применения логического мышления, студенты делают вывод, что реформы были недостаточно последовательными и незавершенными, но их принятие было прогрессивным шагом для развития России, так как способствовало её переходу к капиталистической стадии развития.

Применение второго уровня проблемного обучения истории, предполагающего вовлечение учащихся в процесс коллективного обсуждения предлагаемой темы, способствует превращению студентов из пассивных слушателей в активных участников, решающих в ходе дискуссий определенные исторические дилеммы. Проведение проблемных занятий возможно в том случае, если преподаватель обладает умением формировать у студентов навыки решения сложных задач и направлять мыслительные способности обу- чающихся в объективное русло. Предлагаем методическую разработку практического занятия с использованием проблемного подхода на тему «Реформы П. А. Столыпина ». Преподаватель заранее знакомит студентов с темой будущего занятия, чтобы они смогли изучить необходимый материал для предстоящей дискуссии. Занятие начинается с озвучивания преподавателем проблемного вопроса: «Могло ли успешное осуществление правительственной программы П. А. Столыпина предотвратить революцию в России?». Стратегия решения проблемы подразумевает обсуждение вопросов, касающихся личности Столыпина, его программы, целей и методов его реформ и анализ факторов, помешавших реализации его реформаторских замыслов. Вовлечь студентов в процесс коллективного обсуждения помогают задаваемые преподавателем в ходе дискуссии дополнительные вопросы, способствующие решению поставленной проблемы, например:

- Какие проблемы, существовавшие в России в начале XX века, предполагалось решить в ходе программы Столыпина?

- Можно ли считать, что введение реформ Столыпина было запоздалым?

Проблемная форма занятия уникальна тем, что однозначного ответа на заданные вопросы не существует. Преподавателю важно услышать от студента его собственное аргументированное умозаключение, сделанное на основе его аналитических способностей.

Проблемно-ориентированные занятия третьего уровня сложности могут быть реализованы только при условии приобретения студентами навыков самостоятельного поиска, анализа и отбора всего объема необходимой информации и опыта работы в коллективе. К таким видам практических занятий при преподавании исторических дисциплин относятся следующие: метод «аквариума», «мозговой штурм», «дебаты», «ролевые и деловые игры», «дискуссии» и т. д. [Назырова, с. 316]. В качестве примера предложим форму занятия на тему: «Роль И. В. Сталина в Великой Отечественной войне» в виде имитации судебного процесса. Студенты, ориентируясь на свои предпочтения, распределяют между собой роли, разделяясь при этом на группы: обвинитель и свидетели со стороны обвинения, защитник и свидетели со стороны защиты, а также судебная коллегия в составе трех человек. Главный «судья» руководит всем ходом «судебного процесса», поочередно предоставляя слово сторонам обвинения и защиты, следя при этом за правильным использованием исторических понятий и терминов, документальной обоснованностью 
приводимых фактов, корректностью манеры изложения и оценивая аргументированность доказательств или опровержений. В ходе «судебного расследования» группе защиты предстоит опровергнуть или согласиться с выдвигаемыми обвинениями по отношению к историческому персонажу. Приведем несколько примеров, показывающих, по каким пунктам может строиться обвинение: Сталин незадолго до начала войны обезглавил красную армию (около 10 тысяч командиров было арестовано); заключение Сталиным Московского договора 1939 года способствовало развязыванию второй мировой войны; Сталин опоздал с приведением войск в боевую готовность, в частности игнорировал предупреждения разведчиков о начале войны; Сталин обвиняется в бездействии в первые дни войны; ответственность за поражение в первые месяцы войны лежит именно на Сталине.

Выступления сторон должны строиться по принципу четкого отстаивания своих позиций, так как в конечном итоге «судейская коллегия» должна вынести решение, чьи доводы оказались более убедительными с научной исторической точки зрения. Проведение такого рода занятий является востребованным в качестве одного из прогрессивных видов проблемного обучения.

Таким образом, процесс трансформации исторической науки в настоящее время направлен в сторону отстаивания национальных интересов нашей страны путем вытеснения западноевропейских стандартов. Учитывая, что процессы общественного развития являются крайне противоречивыми, нельзя допускать узкого, слишком политизированного представления о мировом правопорядке. Необходимо использовать в преподавательской практике прогрессивные идеи западных стран и весь опыт, накопленный нашей образовательной системой за прошлые годы. Комплекс приобретенных знаний должен представлять собой объективный анализ достоверных исторических фактов, полученных путем обработки первоисточников. При этом реформирование учебного процесса должно быть направлено в сторону увеличения практических занятий с самостоятельными формами получения знаний.

Практическое исследование методологии преподавания истории в высшей школе должно быть продолжено. Будущее исторической науки не в рамках узкого предметного подхода ее изучения, а в комплексном использовании прогрессивных идей, новых экспериментов и гениальных открытий.
Список литературы

Клешева И. В. Организация проблемного обучения студентов при освоении образовательной программы // Научный журнал НИУ ТМО: Экономика и экологический менеджмент. №3., 2014. С. 205-214.

Назырова E. A. Использование интерактивных методов и приемов обучения при проведении практического занятия на тему «Россия во всемирном историческом процессе» по дисциплине «История» // Вестник Тульского филиала Финуниверситета. №1., 2014. c. 315-318.

Нуриахметова Ф. М., Холоднов В. Г. Новые методы преподавания в техническом вузе // Казанский педагогический журнал. №2., 2014. С. 67-73

Павлова О. А. Проблемы преподавания истории в непрофильных вузах // АНИ Педагогика и психология. №2(19) . Тольятти, 2017. С. 114-117.

Рубаева Э. М. Интерактивные методы обучения в преподавании вариативных курсов по истории // Филологические науки. Вопросы теории и практики. 2016 №5(59) . Тамбов. С. 209-212.

Рычков $A$. В. Какую историю следует изучать в вузе // Омский научный вестник. История. Современность. 2018. №1. С. 82-85.

Сапожникова Н. Д. Метод проекта в преподавании истории и его роль в формировании базовых компетенций студентов // Социокультурное пространство России и зарубежья: общество, обучение, язык. 2014. №3. С. 143-154.

Стожко Д. К., Стожко К. П. Историческое образование в России // Вестник Вятского государственного ун-та. 2017. №11. С. 84-91.

Шалаева С. С., Ножкина И. А. Современная концептуализация предметной направленности истории в образовании // Вестник Саратовского ун-та. 2014. №3(52). С.114-117.

\section{References}

Kleshcheva, I. V. (2014). Organizatsiia problemnogo obucheniia studentov pri osvoenii obrazovatel'noi programmy [Organization of Problem Teaching Students during the Development of the Educational Program]. Nauchnyi zhurnal NIU TMO: Ekonomika i ekologicheskii menedzhment, No. 3, pp. 205-214. St. Petersburg. (In Russian)

Nazyrova, E. A. (2014). Ispol'zovanie interaktivnykh metodov $i$ priemov obucheniia pri provedenii prakticheskogo zaniatiia na temu "Rossiia vo vsemirnom istoricheskom protsesse" po distsipline Istoriia [The Use of Interactive Approaches and Techniques of Teaching during the Practical Lesson in History on the Topic of "Russia in the World Historical Process"]. Tula, Vestnik Tul'skogo filiala Finuniversiteta, No. 1, pp. 315-318. (In Russian)

Nuriakhmetova, F. M., Kholodnov, V. G. (2014). Novye metody prepodavaniia $v$ tekhnicheskom vuze [New Methods of Teaching in Technical University]. Kazanskii pedagogicheskii zhurnal, No. 2, pp. 67-73. (In Russian)

Pavlova, O. A. (2017). Problemy prepodavaniia istorii $v$ neprofil'nykh vuzakh [Problems of Teaching His- 
tory in Non-Core Higher Educational Institutions]. ANI Pedagogika i psikhologiia, No. 2 (19), pp.114-117. Toliatti. (In Russian)

Rubaeva, E. M. (2016). Interaktivnye metody obucheniia $v$ prepodavanii variativnykh kursov po istorii [Interactive Educational Methods in Teaching Elective Courses of History]. Filologicheskie nauki. Voprosy teorii i praktiki, No. 5(59), pp. 209-212. Tambov. (In Russian)

Rychkov, A. V. (2018). Kakuiu istoriiu sleduet izuchat' $v$ vuze [What Kind of History to Study at University]. Omskii nauchnyi vestnik. Istoriia. Sovremennost', No. 1, pp. 82-85. (In Russian)

Sapozhnikova, N. D. (2014). Metod proekta $v$ prepodavanii istorii i ego rol'v formirovanii bazovykh

\section{Гаибова Лейсан Сайфидиновна,} аспирант,

Казанский федеральный университет, 420008, Россия, Казань, Кремлевская, 18. leysan.gaibova@mail.ru kompetentsii studentov [Project Making in Teaching History and Its Role in the Creation of Students' Core Competencies]. Yekaterinburg, Sotsiokul'turnoe prostranstvo Rossii i zarubezh'ia: obshchestvo, obuchenie, iazyk, No. 3, pp. 143-154. (In Russian)

Stozhko, D. K., Stozhko, K. P. (2017). Istoricheskoe obrazovanie $v$ Rossii [Historical Education in Russia]. Viatka, Vestnik Viatskogo gosudarstvennogo un-ta No. 11, pp. 84-91. (In Russian)

Shalaeva, S. S., Nozhkina, I. A. (2014). Sovremennaia kontseptualizatsiia predmetnoi napravlennosti istorii v obrazovanii [Modern Conceptualization of History in Education]. Saratov, Vestnik Saratovskogo un-ta, No. 3(52). pp. 114-117. (In Russian)

The article was submitted on 17.07.2019 Поступила в редакцию 17.07.2019

\section{Gaibova Leysan Saifidinovna,} graduate student, Kazan Federal University, 18 Kremlyovskaya Str., Kazan, 420008, Russian Federation. leysan.gaibova@mail.ru 